\title{
Let op alarmsymptomen bij kinderen met buikpijn
}

Lisette Leeuwen, Jacqueline van Holten, Jan Loeffen, Amerik de Mol, Claudia Keyzer-Dekker

Chronische buikpijn is een van de meest voorkomende klachten bij kinderen. Bij negen van de tien kinderen met acute of chronische buikpijn vinden huisartsen geen somatische oorzaak en volgt de diagnose functionele buikpijn. Toch is het van groot belang om bij een kind met acute of chronische buiklachten altijd alarmsymptomen uit te vragen. Samen met afwijkende bevindingen bij lichamelijk onderzoek maken die spoedoverleg met de kinderarts of chirurg en mogelijk een spoedverwijzing noodzakelijk.

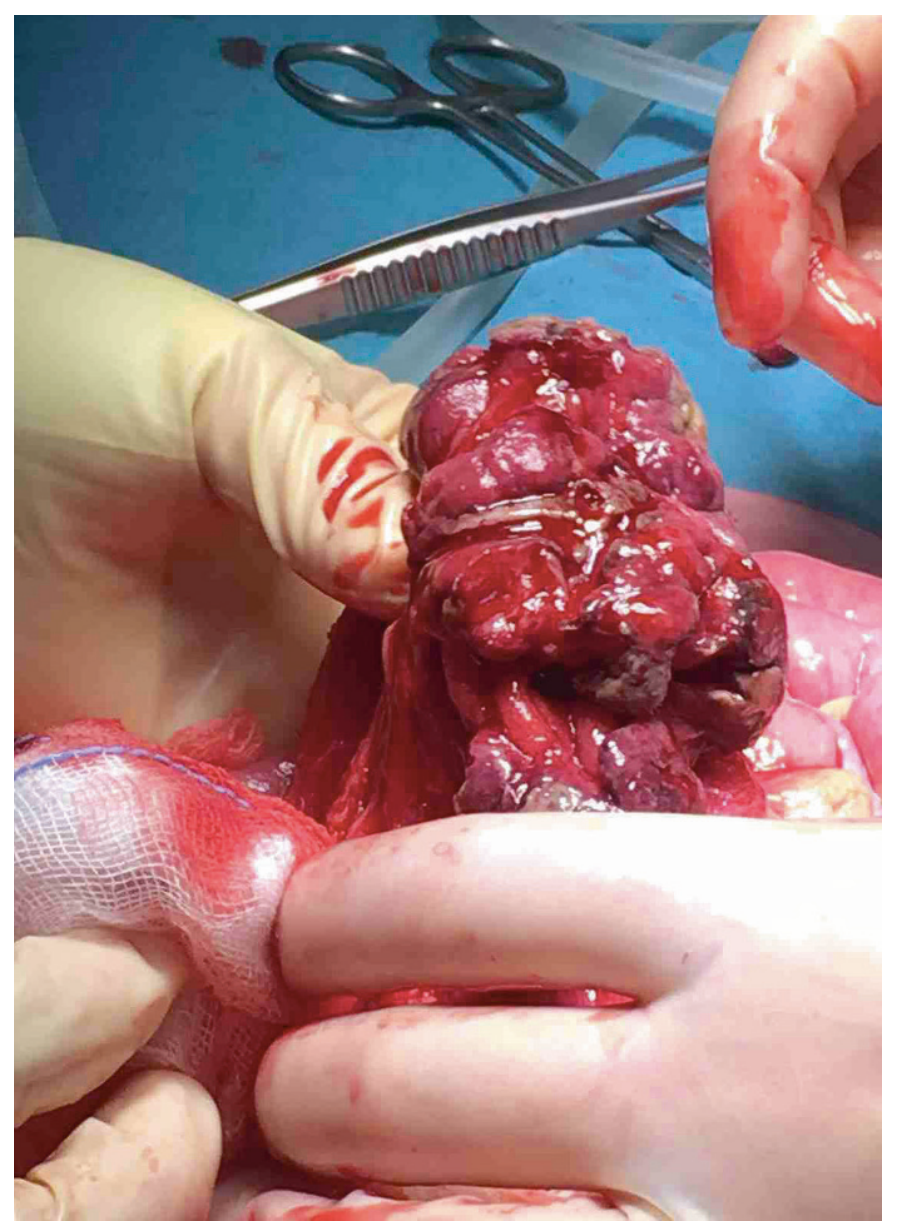

Figuur

Peroperatief beeld van de abdominale tumor die de chirurg bij de patiënt aantrof

\section{CASUS}

Een 6-jarige jongen met blanco voorgeschiedenis komt op het spreekuur vanwege buikpijn waar hij al ruim twee maanden last van heeft. Eén week geleden was de huisarts al gestart met macrogol in verband met buikpijnklachten in combinatie met een verminderde defecatiefrequentie en dunnere, pijnlijke ontlasting. Daarna was een vervolgafspraak voor over twee weken gemaakt. Nu komt de patiënt eerder terug op het spreekuur omdat de buikpijn verergerd is, hij last heeft van bijkomende klachten en zijn moeder zich zorgen maakt. De buikpijn was sinds de vorige afspraak langzaam verergerd, is nu duidelijk gelokaliseerd linksonder in de buik en continu aanwezig. Er is geen sprake van vervoerspijn. Gedurende twee maanden is de ontlasting veranderd en er is sprake van een verminderde defecatiefrequentie en een moeizamere dunnere, pijnlijke ontlasting met geregeld een loze aandrang. De behandeling met macrogol heeft geen verbetering gegeven en er is sinds vandaag ook rectaal bloed- en slijmverlies. De patiënt braakt niet. Hij heeft een verminderde eetlust en er is sprake van gewichtsverlies [onduidelijk is hoeveel]. Vanochtend voelde de patiënt volgens zijn moeder warm aan, maar ze had de temperatuur niet gemeten. De overige tractusanamnese is niet afwijkend. De familieanamnese vermeldt dat moeder onlangs de diagnose de ziekte van Crohn heeft gekregen. Binnen de familie komen geen gevallen van kanker op kinder- of jongvolwassen leeftijd voor.

Bij lichamelijk onderzoek ziet de huisarts een heldere, wat bleke jongen die geen ernstig zieke indruk maakt, maar erg stil is. Zijn lengte is 116 $\mathrm{cm}$, hij weegt $21 \mathrm{~kg}$ [hij is in twee maanden $4 \mathrm{~kg}$ afgevallen [-16\% van het lichaamsgewicht]] en hij heeft een temperatuur van $39,6^{\circ} \mathrm{C}$. Hij heeft een slanke buik, waarin spaarzame peristaltiek te horen is, en bij palpatie is er een drukpijnlijke weerstand linksonder in de buik, zonder tekenen van peritoneale prikkeling. Vanwege de anamnese met alarmsymptomen en de afwijkende bevindingen bij lichamelijk onderzoek zijn er genoeg aanwijzingen om te denken aan een ernstig somatisch probleem. Na overleg met de kinderarts stuurt de huisarts de patiënt door naar de Spoedeisende Eerste Hulp [SEH]. De differentiële diagnose daar luidt: de ziekte van Crohn, colitis ulcerosa, infectieuze colitis, dan wel een invaginatie.

Op de SEH doet de dienstdoende arts verder aanvullend bloed- en beeldvormend onderzoek. Uit het laboratoriumonderzoek blijkt het volgende: een hemoglobine van 5,2 mmol/l [normaal: 6,3-8,4 mmol/l], leukocyten van 7,3 $\times 10^{9} /$ [normaal: 4,3-11,4 $\times 10^{9} /$ ]), trombocyten van $471 \times 10^{9} /$ [ [normaal: $200-370 \times 10^{9} /$ I] en een CRP van $12 \mathrm{mg} / \mathrm{l}$ [normaal: < $10 \mathrm{mg} / \mathrm{l}$ ]. Bij aanvullende echografie van de buik is het beeld van een invaginatie zichtbaar. Hierop verwijst de arts de patiënt door naar een kinderchirurgisch centrum voor nadere diagnostiek en behandeling van de invaginatie. Daar blijkt dat het om een colocolische invaginatie gaat, die met een coloninloopprocedure slechts partieel is op te heffen. Als volgende stap kiest de kinderchirurg voor chirurgische behandeling. Daarbij blijkt dat de invaginatie op een tumor berust. De chirurg besluit tot resectie van het darmgedeelte met tumor van in totaal $20 \mathrm{~cm}$ [figuur], die zij instuurt voor pathologisch onderzoek. Hieruit volgt de diagnose diffuus grootcellig B-cellymfoom. De eerder gevonden anemie bij deze patiënt is dan ook het meest waarschijnlijk multifactorieel van aard en wordt veroorzaakt door de maligniteit, de al langer bestaande verminderde intake en het rectale bloedverlies. Het verdere postoperatieve beloop is ongecompliceerd en de patiënt gaat voor oncologische behandeling naar de afdeling kinderoncologie. Daar krijgt hij verschillende kuren chemotherapie, waarmee het B-cellymfoom met succes wordt behandeld. 
Chronische buikpijn is een van de meest voorkomende klachten bij kinderen, waarbij de huisarts in de meeste gevallen geen somatische oorzaak vindt. In de casus komt een zesjarige jongen op het spreekuur met chronische buikpijnklachten met alarmsymptomen. Ondanks de chroniciteit van de buikklachten heeft deze patiënt een ernstige onderliggende aandoening, een colocolische invaginatie, die blijkt te berusten op een diffuus grootcellig B-cellymfoom. Deze casus laat zien dat het essentieel is om bij zowel acute als chronische buikpijnklachten goed te letten op alarmsymptomen, zoals beschreven in de NHG-Standaard Buikpijn bij kinderen. De Standaard noemt de volgende alarmsymptomen: hevige buikpijn, een ernstig zieke indruk, bloed/gallig braken, sufheid, rectaal bloedverlies, koorts en aanhoudend braken. ${ }^{1}$ De richtlijn Functionele buikpijn van de Nederlandse Vereniging voor Kindergeneeskunde $(\mathrm{NVK})$ vermeldt daarnaast de volgende anamnestische alarmsymptomen: ongewild gewichtsverlies, chronische diarree $(\geq$ drie keer per dag waterige ontlasting, langer dan twee weken),

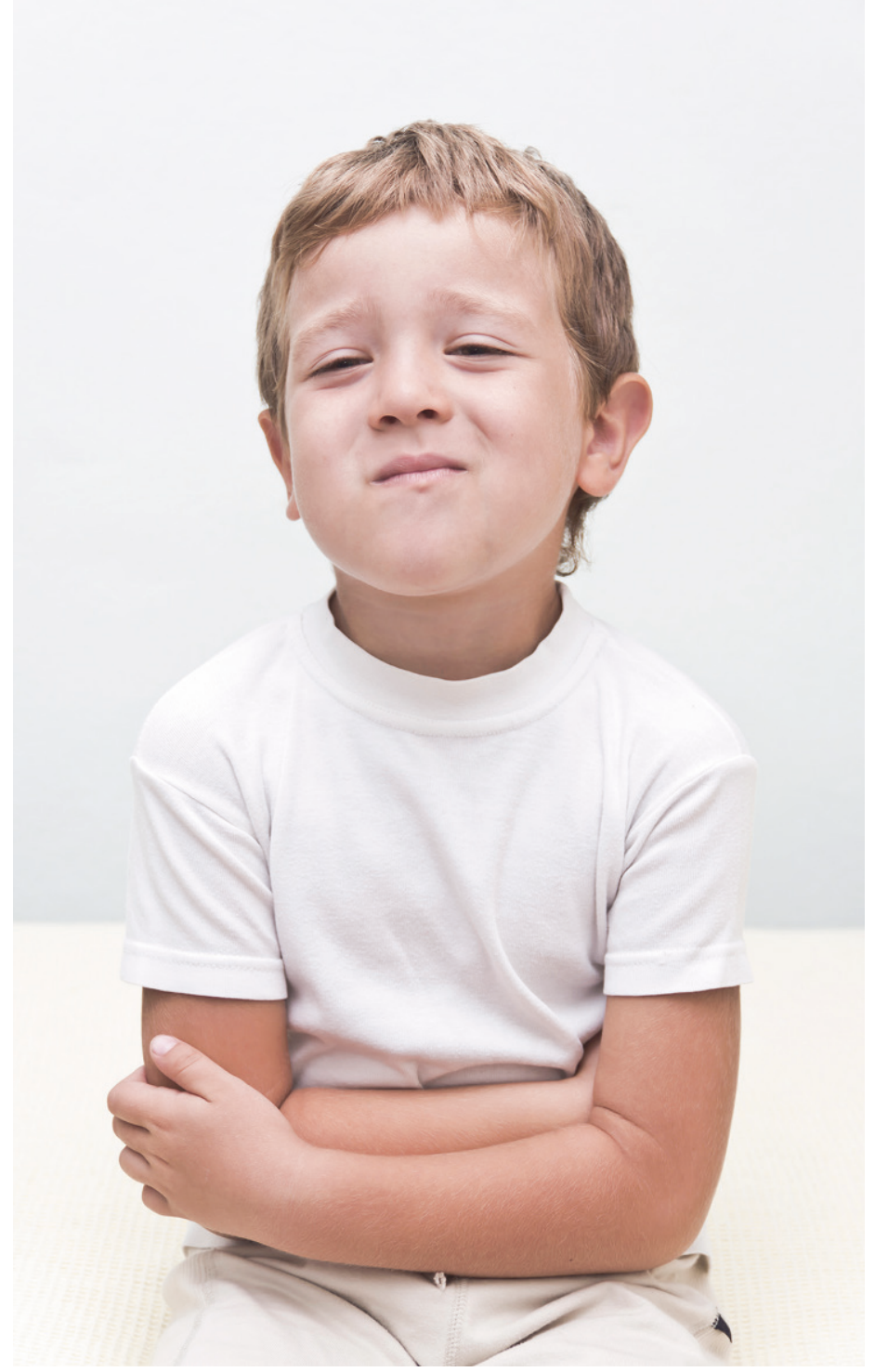

Het uitvragen van alarmsymptomen is essentieel bij kinderen die met acute of chronische buikpijn op het spreekuur komen.

\section{DE KERN}

- Het blijft essentieel om alarmsymptomen uit te vragen bij kinderen die op het spreekuur komen met acute of chronische buikpijnklachten.

- De aanwezigheid van alarmsymptomen in combinatie met afwijkende bevindingen bij lichamelijk onderzoek vormt een indicatie voor spoedoverleg met de kinderarts of chirurg, met zo nodig spoedverwijzing.

- Een invaginatie bij kinderen buiten de typische leeftijdsgroep [drie maanden tot en met twee jaar] of een ongebruikelijke locatie van de invaginatie zijn redenen om te denken aan een onderliggende oorzaak van de invaginatie.

gewrichtsklachten en een positieve familieanamnese voor inflammatoire darmziekten, coeliakie of familiaire mediterrane koorts, ${ }^{2}$ die ook de NHG-Standaard noemt als aanwijzingen voor een somatische oorzaak van buikpijn. ${ }^{1}$

\section{BESCHOUWING}

De prevalentie van chronische buikpijn bij kinderen van twee tot en met achttien jaar varieert van 0,3 tot $19 \%$, afhankelijk van de gehanteerde definitie. ${ }^{3}$ Bij $90 \%$ van de kinderen met chronische buikpijn vindt men geen somatische oorzaak en stelt de arts de diagnose functionele buikpijn. ${ }^{4}$ De aanwezigheid van alarmsymptomen vormt echter een belangrijke aanwijzing voor een somatische oorzaak. In de casus kan de lokalisatie van de pijn linksonder in de buik op obstipatie wijzen. De patiënt had echter eveneens meerdere symptomen die kunnen wijzen op een onderliggende somatische aandoe-

\section{Bij 90\% van de kinderen met chronische buikpijn vindt men geen somatische oorzaak}

ning: rectaal bloedverlies, koorts, ongewild gewichtsverlies en een positieve familieanamnese voor inflammatoire darmziekten. Daarnaast vindt de huisarts bij lichamelijk onderzoek een palpabele massa linksonder in de buik. Wij denken dat de aanwezigheid van alarmsymptomen in combinatie met afwijkende bevindingen na lichamelijk onderzoek bij een kind met buikpijn altijd een reden moet zijn tot spoedoverleg met de kinderarts of chirurg, waarna u de patiënt zo nodig met spoed moet verwijzen.

Een ileocaecale invaginatie is de meest voorkomende oorzaak van intestinale obstructie bij jonge kinderen, die voornamelijk optreedt wanneer kinderen tussen de drie maanden en twee jaar oud zijn.,6 In het grootste gedeelte van de gevallen betreft het een idiopathische invaginatie, maar in ongeveer $6 \%$ van 
de gevallen vindt men een pathologisch leading point. ${ }^{5,7}$ Een colocolische invaginatie zien we slechts bij $1 \%$ van de kinderen met een invaginatie en heeft vaak een onderliggende oorzaak. ${ }^{6,8,9}$ Uit literatuur blijkt dat een juveniele poliep het meest frequent als onderliggende oorzaak voorkomt, ${ }^{8,9}$ maar verschillende case reports beschrijven ook een maligniteit. ${ }^{9}$ Echografisch onderzoek is het meest aangewezen aanvullende onderzoek voor de diagnose invaginatie. Wanneer er geen contra-indicaties zijn, zoals verschijnselen van peritonitis,

\section{Alarmsymptomen zijn: hevige buikpijn, een ernstig zieke indruk, bloed/gallig braken, sufheid, rectaal bloedverlies en aanhoudend braken}

probeert de radioloog met een coloninloopprocedure de invaginatie te reponeren. Bij aanwezigheid van een onderliggende oorzaak is de coloninloopprocedure echter vaak niet succesvol, en moet chirurgische behandeling plaatsvinden..$^{5,78}$ Omdat het risico op een onderliggende oorzaak groter is, moet men na behandeling bij kinderen met een leeftijd onder de drie maanden of boven de twee jaar, of bij een ongebruikelijke locatie van de invaginatie, altijd aanvullend onderzoek naar een eventueel onderliggende oorzaak verrichten.

\section{CONCLUSIE}

De casus illustreert dat het essentieel is om altijd alarmsymptomen uit te vragen bij kinderen die met acute of chronische buikpijnklachten op uw spreekuur komen. De aanwezigheid van alarmsymptomen in combinatie met afwijkende bevindingen bij lichamelijk onderzoek maakt spoedoverleg met de kinderarts of chirurg noodzakelijk, zo nodig gevolgd door spoedverwijzing. Daarnaast laat deze casus zien dat u bij een invaginatie bij kinderen buiten de typische leeftijdsgroep of een ongebruikelijke locatie, extra alert moet zijn op onderliggende pathologie.

\section{DANKBETUIGING}

Wij bedanken Marjon Evera-Preesman en Marieke Gieteling voor hun hulp bij het schrijven van dit artikel.

\section{LITERATUUR}

1. Nederlands Huisartsen Genootschap. NHG-Standaard Buikpijn bij kinderen. Utrecht: NHG, 2012. www.nhg.org

2. Nederlandse Vereniging voor Kindergeneeskunde. Richtlijn: Functionele buikpijn. Utrecht: NVK, 2015.

3. Chitkara DK, Rawat DJ, Talley NJ. The epidemiology of childhood recurrent abdominal pain in Western countries: a systematic review. Am J Gastroenterol 2005;100:1868-75.

De rest van de literatuur staat bij dit artikel op www.henw.org.

Leeuwen L, Van Holten J, Loeffen JL, De Mol AC, Keyzer-Dekker CM. Let op alarmsymptomen bij kinderen met buikpijn. Huisarts Wet 2018;61[2]:53-5. D01:10.1007/s12445-017-1043-2.

Erasmus MC-Sophia Kinderziekenhuis, Afdeling kinderchirurgie, Rotterdam: L. Leeuwen, anios kinderchirurgie, I.leeuwen1@gmail. com; dr. C.M.G. Keyzer-Dekker, kinderchirurg. Erasmus MC-Sophia Kinderziekenhuis, Afdeling radiologie, Rotterdam: J. van Holten, radioloog. Erasmus MC-Sophia Kinderziekenhuis, Afdeling kinderoncologie, Rotterdam: dr. J.L.C.M. Loeffen, kinderoncoloog. Albert Schweitzer Ziekenhuis, Afdeling kindergeneeskunde, Dordrecht: dr. A.C. de Mol, kinderarts-neonatoloog.

Mogelijke belangenverstrengeling: niets aangegeven. 